\title{
Intermittent Complete Atrioventricular Block after Long Term Low-Dose Carbamazepine Therapy with a Serum Concentration Less than the Therapeutic Level
}

\author{
Ayako Ide and Yoshito Kamijo
}

\begin{abstract}
After twelve months of low dose carbamazepine therapy (200 mg daily) for temporal lobe epilepsy, a 66year-old woman presented to the hospital complaining of frequent episodes of sudden dizziness. Because Holter monitoring documented intermittent complete atrioventricular block, the patient was admitted to the hospital when the serum concentration of carbamazepine was $4 \mu \mathrm{g} / \mathrm{mL}$. After discontinuation of carbamazepine, the patient returned to normal sinus rhythm.

The present case suggests that complete atrioventricular block may occur long after initiation of carbamazepine therapy in an older woman even if the daily dosage or the serum concentration of carbamazepine is low.
\end{abstract}

Key words: carbamazepine (CBZ), complete atrioventricular block, temporal lobe epilepsy

(DOI: 10.2169/internalmedicine.46.6280)

\section{Introduction}

Carbamazepine (CBZ) is widely used for the treatment of seizure disorders, trigeminal neuralgia, and affective disorders. Like tricyclic antidepressants, CBZ has quinidine-like effects on cardiac conduction. Bradyarrhythmias or atrioventricular conduction delays have rarely been reported, predominantly in elderly women, during the course of routine treatment with either therapeutic or modestly elevated serum concentrations of the drug (1).

\section{Case Report}

With a complaint of frequent episodes of sudden dizziness, a 66-year-old woman without a previous history of heart disease consulted the Department of Neurology of our hospital, where she had been treated for temporal lobe epilepsy with oral administration of CBZ for twelve months. She had neither family history of sudden death nor relatives with Brugada or sick sinus syndrome (2). The daily dosage of the drug was initially $100 \mathrm{mg}$ for a week and then it was increased to $200 \mathrm{mg}$. The serum concentration of the drug one month, 4 months, and 9 months after the initiation of CBZ therapy was $2.9,3.7$, and $1.6 \mu \mathrm{g} / \mathrm{mL}$, respectively, all of which were below the therapeutic level (6 to $12 \mu \mathrm{g} / \mathrm{mL}$ ) . During this period, the patient had not taken other drugs and 3 electrocardiograms (ECGs) were within normal limits.

The patient was alert and cooperative. Her body temperature was $36.6^{\circ} \mathrm{C}$; blood pressure was $116 / 80 \mathrm{~mm} \mathrm{Hg}$; and heart rate was 62 beats/minute. Physical and neurologic findings, radiologic examinations, including a computed tomography of the brain, and laboratory screening tests were unremarkable. ECG demonstrated normal sinus rhythm. However, Holter monitoring documented intermittent complete atrioventricular block of about 10 seconds duration with ventricular escape (Fig. 1) . She was admitted to the Department of Cardiology for continuous ECG monitoring the following day, and the serum CBZ concentration on admission was $4 \mu \mathrm{g} / \mathrm{mL}$. An external cardiac pacemaker was applied and CBZ, $200 \mathrm{mg}$ daily, was replaced with sodium valproate, $600 \mathrm{mg}$ daily, as an alternative anticonvulsant. The ECG returned to normal sinus rhythm without signs of conduction disturbance on hospital day 2. Continuous ECG monitoring for more 3 days revealed no arrhythmias, and the cardiac pacemaker was removed on hospital day 5 . The 

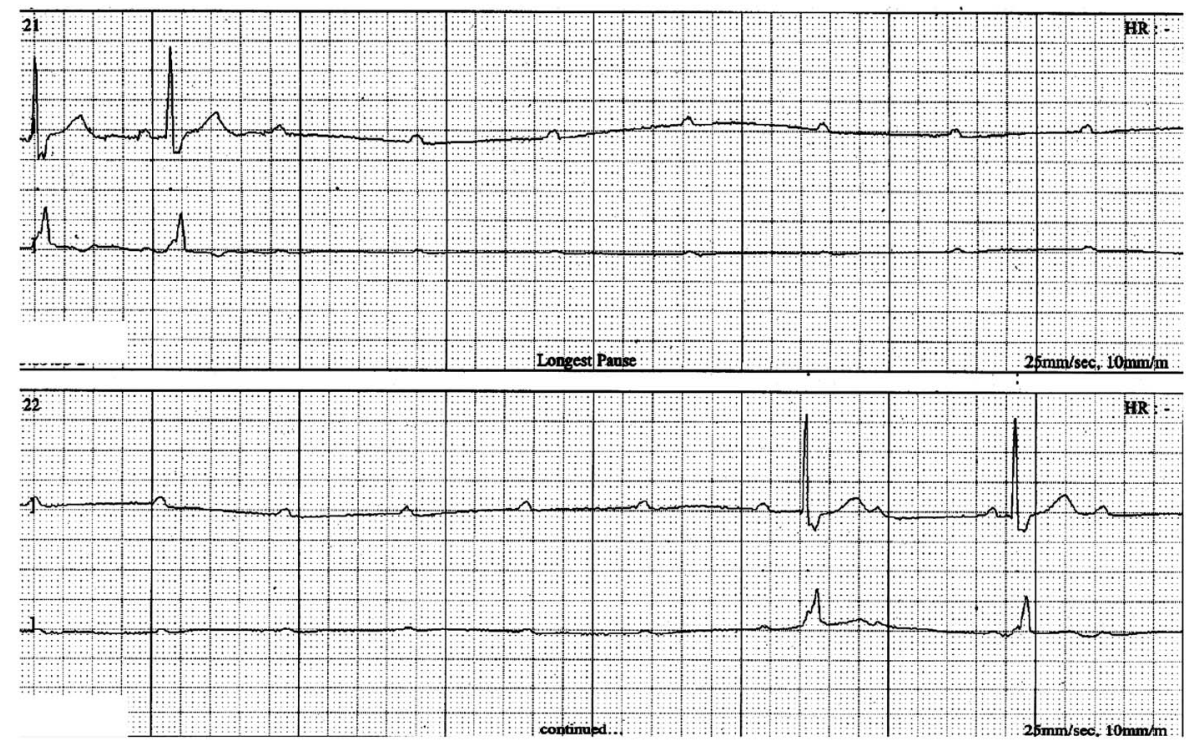

Figure 1. An episode of complete atrioventricular block of 12 seconds duration with ventricular escape recorded by Holter monitoring.

serum concentration of CBZ on hospital days 3 and 6 was 0.9 and $0.7 \mu \mathrm{g} / \mathrm{mL}$, respectively. A ventriculogram, coronary arteriogram, and electrophysiologic examination (a Hisbundle electrogram and an oversuppression test) on hospital day 11 demonstrated no abnormalities. ECG on the same day returned to normal, with PQ and QRS intervals, 0.16 sec and $0.05 \mathrm{sec}$, respectively.

\section{Discussion}

The main hypothetical mechanisms of CBZ are inhibition of voltage-gated $\mathrm{Na}^{+}$channels and activation of voltagegated $\mathrm{K}^{+}$channels (3). As inhibitors of voltage-gated $\mathrm{Na}^{+}$ channels have similar effects on the nerves and heart, CBZ has both neuronal and cardiac effects. CBZ has the property of reducing the rate of Phase 4 depolarization (automaticity) of pacemaker cells of the heart. Thus it may suppress an idioventricular pacemaker and aggravate the bradycardia of complete heart block (4).

In an analysis of all of the previously reported cases of CBZ-induced arrhythmia, two distinct forms were found: sinus tachycardia in the setting of a massive carbamazepine overdose and bradyarrhythmia or atrioventricular conduction delay in the setting of a therapeutic carbamazepine concentration (1). The latter has several characteristics. First, it almost exclusively develops in elderly women, while the former predominantly occurs in younger adults. Secondly, it sometimes occurs after long periods of therapy. Therefore, the relationship between the arrhythmia and the drug use may be overlooked. Third, it is associated with either therapeutic or modestly elevated serum concentrations of the drug. Fourth, it rapidly resolves after discontinuing the drug. Among the various types of the latter toxicity, there have been only a few reports of CBZ-induced complete atrioventricular block, a potentially life-threatening arrhythmia (5-
10) (Table 1). All patients in the previous reports were women older than 55 years of age. All except one had taken more than $400 \mathrm{mg}$ of CBZ daily (therapeutic daily dosages: 200-1200 mg) and they presented with symptoms due to the arrhythmia shortly after the initiation of CBZ therapy (4 to 15 days) (5-9). The serum concentrations of the drug reported in two patients were within the therapeutic range (8, 9). However, Labrecque et al described a 63-year-old woman who presented with exertional dyspnea long (3 years) after the initiation of CBZ therapy (10). The resting ECG was normal but the treadmill stress test showed intermittent complete atrioventricular block. The daily dose of the drug was low $(200 \mathrm{mg})$, but the serum concentration was not reported.

In the present case, complete atrioventricular block appeared one year after the initiation of CBZ therapy in an elderly woman without a previous history of heart disease. As the arrhythmia resolved rapidly following withdrawal of the drug, the drug probably contributed to the arrhythmia. It is most notable that the daily dosage of the drug $(200 \mathrm{mg})$ was low and the serum concentration of the drug inducing complete atrioventricular block $(4 \mu \mathrm{g} / \mathrm{mL})$ was not only less than the therapeutic level but also the lowest concentration causing heart block ever reported. Adding to the case reported by Labrecque et al, the present case suggests that complete atrioventricular block may occur long after the initiation of CBZ therapy in an elderly woman without heart disease even if the daily dose of CBZ is low or the serum concentration of $\mathrm{CBZ}$ is less than the therapeutic level. If dizziness or syncope occurs in elderly women taking any dose of CBZ with any serum concentration of CBZ, the possibility of CBZ-induced complete atrioventricular block should be considered and the cardiac conduction must be evaluated. 
DOI: $10.2169 /$ internalmedicine.46.6280

Table 1. Characteristics of Patients with CBZ-induced Complete Atrioventricular Block

\begin{tabular}{|c|c|c|c|c|c|c|}
\hline Age & $\begin{array}{l}\text { Gender } \\
(\mathrm{M} / \mathrm{F})\end{array}$ & $\begin{array}{l}\text { Daily CBZ dosage } \\
(\mathrm{mg})\end{array}$ & Duration & $\begin{array}{l}\text { Serum CBZ concentration } \\
(\mu \mathrm{g} / \mathrm{mL})\end{array}$ & Symptoms & Source \\
\hline 80 & $\mathrm{~F}$ & 800 & $?$ & $?$ & & * $(4)$ \\
\hline 72 & $F$ & 400 & 4 days & $?$ & $\begin{array}{l}\text { dizziness } \\
\text { syncope }\end{array}$ & Ladefoged (5) \\
\hline 72 & $\mathrm{~F}$ & 400 & 4 days & $?$ & syncope & Boesen (6) \\
\hline 55 & $\mathrm{~F}$ & 800 & 15 days & 8.5 & & Benassi (7) \\
\hline 87 & $\mathrm{~F}$ & 400 & 4 days & therapeutic level & $\begin{array}{l}\text { hypotension } \quad G \\
\text { decreased mentation }\end{array}$ & $\begin{array}{l}\text { Gasperetti (8) } \\
\text { on }\end{array}$ \\
\hline 63 & $\mathrm{~F}$ & 200 & 3 years & $?$ & effort dyspnea & Labrecque (9) \\
\hline 66 & $\mathrm{~F}$ & 200 & 1 years & 4.0 & dizziness & The present case \\
\hline
\end{tabular}

M: male, F: female, Daily CBZ dosage: daily dosage of carbamazepine when complete atrioventricular block occurred, Duration: duration from initiation of CBZ therapy to appearance of complete atrioventricular block, Serum CBZ concentration: serum concentration of carbamazepine when complete atrioventricular block occurred, *: Adverse Drug Reactions Advisory Committee.

\section{References}

1. Makiyama T, Akao M, Tsuji K, et al. High risk for bradyarrhythmic complications in patients with Brugada syndrome caused by SCN5A gene mutations. J Am Coll Cardiol 46: 2100-2006, 2005.

2. Kasarskis EJ, Kuo CS, Berger R, Nelson KR. Carbamazepineinduced cardiac dysfunction. Characterization of two distinct clinical syndromes. Arch Intern Med 152: 186-191, 1992.

3. Armijo JA, Shushtarian M, Valdizan EM, Cuadrado A, Adin J. Ion channels and epilepsy. Curr Pharm Des 11: 1975-2003, 2005.

4. Herzberg L. Carbamazepine and bradycardia. Lancet 1: $1097-$ 1098, 1978.

5. Adverse Drug Reactions Advisory Committee. Carbamazepine. Med J Aust 1: 574, 1979.

6. Ladefoged SD, Mogelvang JC. Total atrioventricular block with syncopes complicating carbamazepine therapy. Acta Med Scand 212: 185-186, 1982.

7. Boesen F, Anderson EB, Jensen EK, Ladefoged SD. Cardiac conduction disturbances during carbamazepine therapy. Acta Neurol Scand 68: 49-52, 1983.

8. Benassi E, Bo G-P, Cocito L, Maffini M, Loeb C. Carbamazepine and cardiac conduction disturbances. Ann Neurol 22: 280-281, 1987.

9. Gasperetti CM. Conduction abnormalities complicating carbamazepine therapy. Am J Med 82: 381-000, 1987.

10. Labrecque J, Cote MA, Vincent P. Carbamazepine-induced atrioventricular block. Am J Psychiatry 149: 572-573, 1992.

\section{(C) 2007 The Japanese Society of Internal Medicine http://www.naika.or.jp/imindex.html}

